\title{
Transposition of Knowledge: Encountering Proportionality in an Algebra Task
}

\author{
Anna. L. V. Lundberg ${ }^{1}$ - Cecilia Kilhamn ${ }^{1}$
}

Received: 22 January 2015 / Accepted: 2 November 2016/Published online: 7 December 2016

(C) The Author(s) 2016. This article is published with open access at Springerlink.com

\begin{abstract}
This article reports on an analysis of the process in which knowledge to be taught was transposed into knowledge actually taught, concerning a task including proportional relationships in an algebra setting in a grade 6 classroom. We identified affordances and constraints of the task by describing the mathematical praxeology of the two different types of knowledge exposed, in the task as such and in the activity of the classroom. Through the teacher's explicit process of reasoning, modeling, revising, solving, and repeatedly explaining the task, we found that the transposition of knowledge was seriously affected by the contextualization of the task. Modeling word problems about everyday situations has its limitations and can, as in this case, make the problem unsolvable unless it is accepted as a "textbook task" disguised as real but adjusted to the norms of school mathematics. Such constraints may obscure mathematical ideas afforded by the task. We conclude that learning opportunities embedded in a task do not necessarily surface when a task is treated in a classroom setting.
\end{abstract}

Keywords Algebra - Anthropological theory of the didactic (ATD) - Contextualization · Proportional reasoning $\cdot$ Textbook tasks

\section{Introduction}

When a mathematics textbook task is designed for school use, it is generally intended to support the learning of some particular mathematical content. It is therefore relevant to investigate in what ways a task used in a classroom context offers opportunities for

Anna. L. V. Lundberg

Anna.Lundberg@gu.se

Cecilia Kilhamn

Cecilia.Kilhamn@gu.se

1 Department of Pedagogical, Curricular and Professional Studies, University of Gothenburg, Box 300, 40530 Gothenburg, Sweden 
learning, and what parts of the knowledge to be taught are actually taught. Task research is often conducted as an in-depth analysis of the text in the task (Bayazit, 2013; Boesen, 2006; Brändström, 2005; da Ponte \& Marques, 2007; Dowling, 1998; Haggarty \& Pepin, 2002; Jablonka \& Johansson, 2010; Lithner, 2008), while the way in which tasks are treated in classrooms is absent. Additionally, classroom studies often take textbooks for granted and do not analyze textbook tasks in detail. In the Nordic countries in particular, there is a need for more content-related classroom studies (Klette, 2007). Few studies analyze how specific textbook tasks are interpreted in the classroom in relation to affordances and constraints of the tasks per se. In this study, we set out to investigate what happens to potential learning opportunities of a textbook task in an algebra lesson.

The task in focus in this study is an algebraic description of a proportional relationship, which can also be regarded as a modeling task with the underlying mathematical idea of a proportional relationship. Proportional and multiplicative reasoning can be regarded as the gateway to success in studying algebra. Langrall and Swafford (2000) claim that proportional reasoning is foundational to the development of algebraic reasoning and must be developed over a long period of time, not isolated in a single unit. This could be done by providing students with opportunities to model proportional relationships in situations where two or more measures change in relationship to each other (Lamon, 1993; Langrall \& Swafford, 2000; Singh, 2000). Vergnaud (1983) describes multiplication and division tasks involving fractions and ratios as special cases of direct proportion tasks. A task including direct proportions and multiplicative structures could therefore be used to highlight proportional reasoning in algebraic settings.

We use the term "type of task" as defined by Chevallard (2006) and will apply it to analyze the essence and treatment of a task found in a mathematical textbook. Tasks are seen as cultural artifacts, influenced by the mathematics culture at large as well as by the time and place in which they are created and used. Tasks are a valuable instrument in mathematics education, particularly in a textbook intense teaching culture as is the one in Sweden (Johansson, 2006). For many Swedish teachers, the textbook embodies and is assumed to cover the knowledge to be taught. In a large set of video data, we observed a compelling instance illustrating how proportional reasoning appears in an algebra task interpreted, solved, and explained in the moment of teaching. The teacher models, makes assumptions, and revises her model while thinking aloud, offering a unique opportunity to study the last step of the process of didactic transposition. The task itself is unsolvable unless modeled with assumptions incompatible with experience. We find it plausible that the process of transposition exposed by this teacher resembles one that other teachers go through when preparing lessons, transposing knowledge embedded in textbooks and curricular documents into knowledge actually taught in the classroom.

Our aim is to explore the last step of the didactic transposition of knowledge in a single case study concerning a task related to algebra and proportionality found in a Swedish mathematics textbook and dealt with in a grade 6 classroom. The notion of didactic transposition comes from the Anthropological Theory (Chevallard, 2006), to point out the transformations of knowledge of an object or a body of knowledge when it passes through the education system, from the moment it is produced, placed in use, selected, reorganized and specified in curriculum guidelines and textbooks, and 
contrived in instruction and activities carried out in classrooms. The theory adopts an institutional conception of mathematical activity starting from the assumption that mathematics, like other human activity, is produced, taught, learned, and diffused in social institutions. School knowledge content and form in these activities is a consequence of the didactic transposition process, i.e. a change or adaptation of selected existing knowledge to "teachable" knowledge. School mathematics can be analyzed by considering four types of knowledge as it passes through the institutional system from scholarly knowledge to knowledge to be taught, knowledge actually taught, and knowledge learned by students. We focus on the transposition between knowledge to be taught as expressed in the context of the textbook and potentially included in the task and knowledge actually taught within a classroom setting (Bosch \& Gascón, 2006). In particular, we focus on this transposition in relation to the concept of proportionality outlined in the national curriculum because of its role as a foundation for algebraic reasoning. Types of tasks, techniques, technologies, and theories form what is called mathematical praxeologies. They are collective constructions shared by groups of human beings organized in institutions and an inseparable union of (a) the praxis or "know how," including types of tasks and techniques to carry them out, and (b) the logos or "know why," containing the technology that explains and justifies the techniques and the theory that justifies the technology (Bosch, García, Gascón \& Ruiz Higueras, 2006; Chevallard, 2006). The notion of praxeology is used to elaborate reference epistemological models (REM) to be applied by researchers as a tool to describe and analyze the specific mathematical contents that appear in the observed teaching and learning processes (Bosch \& Gascón, 2006; Florensa, Bosch \& Gascón, 2015).

From a teacher's point of view, the textbook represents the knowledge to be taught, together with the national curriculum. Table 1 presents details about how algebra and proportionality are described in the curriculum, presented as two different blocks of core content. Despite the rather vague description of the mathematical content in this document, it serves in the Swedish school context as fundamental guidelines for

Table 1 Knowledge to be taught

\begin{tabular}{|c|c|}
\hline Logos: & Core content block: Algebra \\
\hline $\begin{array}{l}\text { Theoretical models } \\
\text { (Theory and technology) }\end{array}$ & 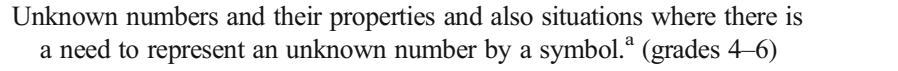 \\
\hline \multirow{3}{*}{$\begin{array}{l}\text { Praxis: } \\
\text { (Types of tasks and } \\
\quad \text { techniques) }\end{array}$} & $\begin{array}{l}\text { Core content block: Relationships and change } \\
\text { Different proportional relationships, including doubling and halving. (grades 1-3). } \\
\text { Proportionality and percentage and their relationship. (grades } 4-6 \text { ) }\end{array}$ \\
\hline & $\begin{array}{l}\text { Core content block: Algebra } \\
\text { Unknown numbers and their properties and also situations where there is } \\
\text { a need to represent an unknown number by a symbol. }{ }^{\text {a }} \text { (grades } 4-6 \text { ) } \\
\text { Simple algebraic expressions and equations in situations that are relevant } \\
\text { for pupils. } \text {. (grades } 4-6 \text { ) }_{\text {Methods of solving simple equations. } .^{\text {a }} \text { (grades } 4-6 \text { ) }}\end{array}$ \\
\hline & $\begin{array}{l}\text { Core content block: Relationships and change } \\
\text { Proportional reasoning including doubling and halving. (grades 1-3). Graphs } \\
\quad \text { for expressing different types of proportional relationships. }{ }^{\text {a }} \text { (grades } 4-6 \text { ) }\end{array}$ \\
\hline
\end{tabular}

${ }^{\text {a }}$ Swedish National Agency for Education (2011, p. 60-62) 
teachers and textbook authors (Johansson, 2006). This study focuses on the transposition work done by the teacher. The mathematical praxeologies serve as useful tools in our endeavor to analyze the task itself as the mathematical knowledge to be taught, and the acts and utterances of the teacher in her process of interpreting and explaining the task as the knowledge actually taught, uncovering the last part of the transposition between these types of knowledge.

Research on teacher's use of curriculum has highlighted the teacher's role in the enactment and meaning making of curriculum (Remillard, 2005). In line with Remillard, we believe that a written curriculum cannot prescribe the actual curriculum implemented in the classroom. Since knowledge described in the curriculum is interpreted and altered by the teacher before it is taught, Remillard calls for research into the participatory relationship between teacher and curriculum. Chevallard's (2006) notion of didactic transposition puts focus on the process of how mathematical scholarly knowledge is transformed between the intended, the planned, and the enacted curriculum. In textbooks, some mathematical ideas are explicitly organized in topics and units whereas other ideas, such as problem solving, span across many topics permeating different units. As a result, some mathematical ideas are more explicit than others. Our research interest in proportionality and proportional reasoning is related to the fact that proportionality was new in the Swedish curriculum for grade 6 at the time of the study and did not have a separate unit in the textbook. The teacher is thus responsible to find situations where proportional reasoning can be taught. Proportional relationships can be described as a mathematical "big idea" spanning different topics such as algebra, calculus, scaling, and rational number arithmetic. The task in question appears in the algebra unit and could be seen as intended to support the teaching of algebra but also to embody a potential to teach aspects of proportionality. In relation to the specific task and the work of one teacher, we pose the following research question: What are the affordances and constraints of the chosen task as it is presented in the textbook, and what happens to these in the final step of transposition into knowledge actually taught in the classroom? Finally, we will discuss how the results of our analysis could be of use for textbook authors.

\section{Proportionality and Proportional Reasoning in the REM}

The reference epistemological model (REM) used here includes two common definitions of proportionality constituting the logos of the mathematical praxeology. In the Swedish school context, proportionality is often defined as a linear relation such that $y=$ $a \cdot x$ where $y$ and $x$ are real numbers and $a$ is the proportionality constant and explicitly mentioned in connection with linear functions. Miyakawa and Winsløw (2009) call this dynamic proportionality, as opposed to static proportionality. The pairs $(a, b)$ and $(c, d)$ of positive real numbers show a static proportionality, $(a, b):(c, d)$, if $a \cdot d=b \cdot c$ or, equivalently, $\frac{a}{b}=\frac{c}{d}$. Static proportionality is closely related to fractions and ratios.

Proportionality can be expressed as internal or external depending on whether it is a relation within or between measure spaces ${ }^{1}$ (Freudenthal, 1983). Internal proportionality is a relation within the same measure space, e.g. $\left(\frac{s_{1}}{s_{2}}=\frac{t_{1}}{t_{2}}\right)$, where $s_{1}$ and $s_{2}$ belong to

\footnotetext{
${ }^{1}$ A measure space $\mathfrak{B}$ consists of so-called concrete numbers $q S$, where $q$ is a positive rational number and $\mathrm{S}$ a measure unit (Kirsch, 1969; Vergnaud, 1988)
} 
measure space $\mathfrak{B}$ (meters) and $t_{1}$ and $t_{2}$ belong to $\mathfrak{B}$ (seconds). External proportionality is a relation between elements in different measure spaces $\left(\frac{s_{1}}{t_{1}}=\frac{s_{2}}{t_{2}}\right)$. Both internal and external proportionality relates to the static proportionality in the logos.

The counterpart of proportionality in praxis is proportional reasoning, described by Lamon (2007, p. 637) as:

[...] supplying support of claims made about the structural relationships among four quantities, (say, a, b, c, d) in a context simultaneously involving covariance of quantities and invariance of ratios or products; this would consist of the ability to extend the same relationship to other pairs of quantities.

Proportional reasoning can incorporate both verbal descriptions and symbolically represented relationships described by the logos. Students need to be aware of when and why the different definitions are useful and how these relate to different solution techniques and useful representations described as the praxis part of the praxeology. Flexibility in proportional reasoning and the use of different techniques and representations to supply arguments is commonly developed in school mathematics using a variety of tasks. An equation could be set up as a linear function (dynamic proportionality) or as equivalent ratios (static proportionality) and solved accordingly using techniques such as recollection of number facts, cross multiplication, formal equation solving methods, or graphic representations. The task analyzed in this study, henceforth referred to as The Lemon Squash Task, is an algebraic task involving a proportional relationship.

\section{Contextualization}

The ability to constitute the world around oneself, under different systems of concepts contained in various activities, is central to a sociocultural perspective on learning. According to Vygotsky (1986) word meaning reflects a generalized concept and word sense depends on the context in which the word appears. In line with this idea, we consider any mathematical concept as consisting of a word and its definition, i.e. its meaning, along with the sense it gains through the different contexts where it appears. People make sense of concepts by using them in different contexts. Using the term contextualization to mean the specific ways in which an object or episode is constituted (Säljö, 2005), decontextualization in mathematics assumes abstracting properties from specific examples and then combining them to constitute general mathematical objects and relations. When an underlying structure or mathematical idea is moved from one context to another, we speak of a recontextualization. (Linell, 1992; Säljö, 2005). When textbook authors try to make a problem authentic and familiar, for example by using a mixture problem to introduce the idea of proportional relationships, this also brings along a load of new assumptions and possible difficulties. The realistic touch of the question increases its cultural burden (Wyndhamn \& Säljö, 1997). Everyday contexts will trigger the use of out-of-school knowledge, everyday concepts and common sense, although these may not always be applicable (Sullivan, Zevenbergen \& Mousley, 2003). The Lemon Squash Task is interesting because it entails a switch between everyday concepts and scientific concepts (Vygotsky, 1986). 
[...] school arithmetic word problems seem to be perceived by students as a capricious kind of school tasks that are separated from the real world and that have to be solved by means of certain computational techniques on the given numerical data, ignoring real-world knowledge and even accepting conditions about the problem context that are empirically false. (Verschaffel, Greer \& De Corte, 2000, p. 12)

A textbook problem intended to be a "realistic" problem is neither mathematics nor a real-world problem, argues Jablonka and Gellert (2007). Since the problem is constructed mathematically, it only retains a trace of the non-mathematical significance. The result is often that it is no longer possible to evaluate the solution from a practical point of view. The familiar context produces a solution that fails to make sense in the real situation. In a sociocultural perspective, modeling implies a coordination of mathematical notions and operations with objects and events in a physical reality. Mathematics is used as mediational means to make claims about relationships in the world (Verschaffel, Greer \& De Corte, 2000; Wyndhamn \& Säljö, 1997).

The Lemon Squash Task involves a mixture of juice, sugar, and water and the proportional relations between them. Mixture problems differ from rate problems in that the elements in a mixture create a new object (e.g. Karplus, Pulos \& Stage, 1983; Mellar, 1991; Noelting, 1980; Nunes, Desli \& Bell, 2003; Wright, 2014). Tourniaire and Pulos (1985) describe three context variables that affect the difficulty of a mixture task; firstly, the mixture as such, being an object where the different volume parts are not distinct and therefore more difficult to handle; secondly, the inclusion of continuous quantities which are more difficult to visualize than discreet quantities; and finally, the familiarity of the context, i.e. if the context is familiar the task is often found to be easier. The Lemon Squash Task belongs to the group of mixture problems but differs from most problems previously described by being a mixture of solids dissolving in liquids. A similar mixture was described by Nunes, Desli and Bell (2003) and Howe, Nunes and Bryant (2011), but in these studies, the problem is concerned with taste rather than volume. The Lemon Squash Task is problematic because of the continuous quantities and the mixture of solid sugar in liquids.

The interpretation of a task is also constrained by certain norms of school mathematics, regulated by the didactical contract (Brousseau, 1997). One example of such a norm is that all numbers present in a problem are to be used and operated on, and no more information is needed to solve the task (Verschaffel et al., 2000). We hypothesize that the perception of word problems as problems that are only artificially real is part of the norms of school mathematics also adopted by teachers in their work with textbooks. The didactic transposition of mathematical knowledge is begun by textbook authors through their construction of tasks in relation to various units in a textbook. Although the Lemon Squash Task concerns mixing substances, both teacher and students know it is not really about mixing a drink but about some mathematical idea, in this case, a proportional relationship or the introduction of an algebraic expression with an unknown number.

\section{Method and Setting}

Data for our analysis is taken from a larger set of video data collected within an international project where several teachers, without intervention, were video recorded 
during four consecutive algebra lessons. In the Swedish data, four qualified teachers taught grade 6, student age 12-13 years. The teachers were recruited to the study after showing interest in participating as a means of professional development. Three cameras were used during the recordings in order to catch the teacher, a focus group, and the whole class. Also, written material was collected and a short post-lesson interview was conducted after each lesson. The analyzed lessons from one grade 6 classroom form a single case study where one teacher explicitly reveals the constraints coming from the didactic transposition. The teacher in question has a 10-year teaching experience. During the recorded lessons, the textbook plays an important role in her teaching.

As an approach to the analysis of the collected data, we draw on interaction analysis (Jordan \& Henderson, 1995). The method includes creating content logs to outline the recorded lesson as soon as possible and conducting collaborative viewings with other researchers. Video sessions were conducted with group members of the project in order to generate observations and hypotheses about the activity on the tape.

Proposed hypotheses must be of the kind for which the tape in question (or some related tape) could provide confirming or disconfirming evidence. The idea is to ground assertions about what is happening on the tape in the materials at hand.

(Jordan \& Henderson, 1995, p. 44)

When looking through the Swedish data, the analytical focus was to find episodes that would give insight into the teacher's work of didactic transposition. One teacher's treatment of the Lemon Squash Task caught our interest because teacher-student interaction around the task appeared seven times in the recordings of one of the grade 6 classrooms. These episodes were selected to form a single case study. The episodes were carefully transcribed and partially translated into English. In the excerpts presented here, $\mathrm{T}$ is used for teacher, $\mathrm{S}$ for student, and (.) indicates a pause. The seven episodes were reviewed many times, and also viewed by the research group to establish agreement about the phenomenon in line with Jordan and Henderson (1995) thereby increasing the inter-rater reliability.

The task was found in the algebra unit in a commonly used grade 6 textbook (Carlsson, Liljegren \& Picetti, 2004). Although proportionality is part of the current national curriculum (Swedish National Agency for Education, 2011) it is not treated as an explicit topic in this textbook but appears in various units and tasks. Therefore, teachers are responsible in their teaching to bring forward tasks and techniques withholding proportional reasoning and proportionality. In this classroom, mathematics lessons consist of a short whole class introduction followed by individual deskwork while the teacher circulates through the classroom. Students work through the textbook unit at their own pace, implying that they rarely work on the same task at the same time. This is a common practice in Sweden (Carlgren, Klette, Myrdal, Schnack \& Simola, 2006). First, an analysis of the praxeology of the task as it appears in the textbook was made, focusing on embedded aspects of proportionality and algebra, since it appears in the algebra unit and concerns proportional relationships. Although the textbook authors make many choices that influence the teachers' interpretation of what knowledge is to be taught, in this study, we take the textbook to represent the knowledge to be taught and focus on the transposition of that knowledge by the teacher. Secondly 
an analysis of the knowledge actually taught was made. We acknowledge that our backgrounds as teacher and teacher educator has influenced our analysis (Goodwin, 1994). For that reason, other researchers have been included in some of the video sessions, and a first analysis of the task was discussed thoroughly at the ICMI study 22 conference. (Lundberg \& Kilhamn, 2013)

\section{The Lemon Squash Task in the Context of the Textbook}

The algebra unit in the textbook spans over 26 pages, including 127 tasks with a strong emphasis on the learning of algebraic symbolic language and the meaning of the terms equation, expression, and variable. There are six pages in the teacher's guide on the algebra unit and an additional eight worksheets. Tutorial notes are given in general terms and no guidance is given in relation to any particular task. The text in the guide concerning the page where the Lemon Squash Task appears is as follows (Translation Lundberg \& Kilhamn)

An expression consists of one or more variables written with letters and sometimes one or more numbers. An expression does not have a fixed value until the value of each variable is known. That is a big difference compared to an equation. The letters in an equation have a fixed value and it is that value you find by solving the equation. Therefore the letters in an equation are not variables. (Carlsson et al., 2004, p. 64).

Later on in the teacher guide, the technique suggested to solve equations is to use trial and error. The Lemon Squash Task ${ }^{2}$ appears under the heading "Expressions". There are two pages where the types of tasks involve writing expressions by translating from verbal to algebraic representation or vice versa, followed by one page with tasks where an expression is given and a number is to be inserted in the place of a letter, using simple addition, subtraction, multiplication, or division facts as solution techniques. No equationsolving technique is introduced. No theoretical models of either algebra or proportionality are made explicit in the unit. However, many of the expressions reveal multiplicative relations such as "double as much as y" or "a fourth of y," where proportional reasoning would be a useful solution technique. Only one measure space at the time is included, e.g. age and length. The last task is the Lemon Squash Task. We believe that the authors of the textbook chose the context of mixing and drinking this type of drink, usually called saft $t^{3}$, because it is a common point of reference for Swedish children. Figure 1 describes task 47 $\& 48$ from the textbook (Carlsson et al., 2004, p. 103).

\section{Results}

The results will be presented in two parts. First, a content analysis of the knowledge to be taught in the Lemon Squash Task is made, highlighting its affordances and

\footnotetext{
${ }^{2}$ We have chosen to use the name "Lemon Squash" although the Swedish name for the task is "Törstsläckare" which literally means "Thirst reliever."

${ }^{3}$ Saft is a Swedish sweet drink, which is close to the British cordial. Traditionally, it is made from the juice of berries mixed with sugar and water.
} 
47. You want to mix "Lemon Squash". You

have $5 \mathrm{dl}$ lemon juice, $x=5 \mathrm{dl}$. How much

do you need of:

a) Water?

b) Sugar?

$48 *$. How much lemon juice is there in $7 \mathrm{dl}$

mixed "Lemon Squash"?

Fig. 1 The Lemon Squash Task in the textbook (Translation by Lundberg \& Kilhamn)

constraints in relation to the mathematical topics algebra and proportionality. By analyzing the potential in the task we provide possible mathematical and didactical meanings of the knowledge to be taught. The second part presents the classroom analysis, describing the transposition into knowledge actually taught, i.e how the task was treated by the teacher in a grade 6 classroom in a Swedish school.

\section{Affordances and Constraints of the Task as Knowledge to Be Taught}

The Lemon Squash Task includes three subtasks, where the first two $(47 \mathrm{a}, \mathrm{b})$ are both closed questions with a unique solution within one measure space: $\mathfrak{B}(d l)$. Proportions of the three ingredients are given in symbolic representation in the "recipe," and the student is asked to interpret the algebraic expressions $x$ lemon juice, $2 x$ water, and $x / 2$ sugar. There are two ways of solving these tasks. The interpretation of $2 x$ water and $x / 2$ sugar leads to static internal proportional reasoning through a translation into "twice as much water and half as much sugar as the amount of lemon juice." The technique here is to reason about the most basic proportional relations of double and half, $\left(\frac{\text { water }}{\text { lemon juice }}=\frac{2}{1}\right.$ and $\left.\frac{\text { sugar }}{\text { lemon juice }}=\frac{1}{2}\right)$. Translating from a symbolic to verbal representation gives $x$ a meaning and makes use of proportional reasoning within the recipe, i.e. how the volume parts relate to each other. Another solution technique is to move into an arithmetic representation, exchanging $x$ for 5 in each expression to interpret water as $2 \cdot 5=10$ and sugar as $5 / 2=2.5$. The letter $x$ could be interpreted as a placeholder for an unknown number rather than as a variable in a proportional relationship; hence, the technique could be utilized without proportional reasoning. A potential learning opportunity for task 47 could be to develop meaningful interpretations of algebraic expressions through proportional reasoning, thus developing techniques closely attached to theoretical models. Or, it could be used to practice the procedural technique of replacing $x$ in an expression to calculate a value using arithmetic techniques.

Task 48, however, is much more complex involving the total volume of a mixture of fluids and solid matter. There is also a need to impose the idea of volume parts. Here, we find the first and most striking constraint of the task, namely the fact that mixing these ingredients in reality and the intended mathematics content are not aligned. We will deal more with this constraint in the classroom analysis and the discussion and, for 
now, analyze what we interpret as the intended mathematical content, i.e. the knowledge to be taught. The Lemon Squash Task involves all the three context variables that often appear in mixture tasks according to Tourniaire and Pulos (1985). It is a mixture where volume parts are not distinctly visible, it deals with continuous quantities, and it supplies a familiar context. However, the familiar context of the recipe does not afford the use of a letter to represent the unknown.

Lemon Squash is made of three ingredients: lemon juice, water, and sugar. Task 48 gives the proportions of these ingredients as algebraic expressions and the total amount as a set quantity asking for the amount of water. It can be seen as a proportionality task by considering how the total number of volume parts in one batch is related to the total quantity. To find out the number of volume parts in a batch, the algebraic expressions in the recipe need to be translated into verbal representations giving $x$ the meaning of one part. One part of lemon juice, two parts of water, and half a part of sugar adds up to $3 \frac{1}{2}$ parts. We then want to find out how much one part is when $3 \frac{1}{2}$ parts is $7 \mathrm{dL}$. This can be described as an external static proportionality where $7 \mathrm{dL}: 31 \frac{1}{2}$ parts $=x \mathrm{dL}: 1$ part, $\left(\frac{7}{3.5}=\frac{x}{1}\right)$ , or as an internal static proportionality where 1 part: $3 \frac{1}{2}$ parts $=x \mathrm{dL}: 7 \mathrm{dL},\left(\frac{1}{3.5}=\frac{x}{7}\right)$. This theoretical model supports different solution techniques, for example by using number facts $\left(7\right.$ is $\left.2 \cdot 3 \frac{1}{2}\right)$ or a cross multiplication algorithm $\left(7 \cdot 1=3 \frac{1}{2} \cdot x\right)$. Proportional reasoning in combination with a trial and error approach is also possible, i.e. if each part is $1 \mathrm{dL}$ the total would be $3 \frac{1}{2} \mathrm{dL}$, but 7 is twice as much as $3 \frac{1}{2}$, so each part must therefore be twice as much as 1 .

When Task 48 is interpreted as a linear function, the total quantity can be expressed as $y=a \cdot x$. If $a$ is a scalar operator (Vergnaud, 1988) then $f(\mathrm{x})=x \cdot f(1)$. We know that $f(1)=$ $3 \frac{1}{2}$. To find $f(x)=7$ we see that $7=x \cdot 3 \frac{1}{2}$. In this case, the meaning of $x$ is the number of times we need to take the whole mixture (all the volume parts) to get the total amount of $7 \mathrm{dL}$. However, if $a$ is a function operator (ibid), then $f(x)=3 \frac{1}{2} \cdot x$ and the meaning of $x$ is what quantity we need to take $3 \frac{1}{2}$ times to get 7 . In either case, the proportionality is dynamic. Whichever way the linear function is interpreted, a graphic representation could be a useful solution technique. A more primitive example of proportional reasoning is to consider only the internal static proportions among the ingredients and use a trial and error solution technique. If we have $1 \mathrm{dL}$ of lemon juice, we would need $2 \mathrm{dL}$ of water and $1 / 2$ $\mathrm{dL}$ of sugar, which add to $3 \frac{1}{2}$, which is less than 7; so, we try with $2 \mathrm{dL}$ of lemon juice.

Seen as a proportionality task, the Lemon Squash Task can be said to afford the theory of different types of proportionality (static or dynamic), and different solution techniques, making use of translations between symbolic and verbal representations, which is the main goal of the algebra unit. A different approach to the task is to stay within the algebraic representation and model an equation by adding the expressions: $x+2 x+\frac{x}{2}=7$. Again, the solution technique can either be one of trial and error or of formally solving the equation for $x$ to get $x=2$. In this case, the task affords the opportunity for modeling an equation with one variable and an appropriate equation solving technique. Because the expressions are already given, the modeling part is limited. No switch of representation is necessary, although it is possible to translate the algebraic equation into a visual or concrete representation instead of using a formal equation solving procedure, or to use the technique of trial and error. Table 2 summarizes the techniques from REM as they realte to the two tasks. 
Table 2 Summary of techniques from the REM applied to task 47 and 48

\begin{tabular}{|c|c|c|c|}
\hline Logos & Technique & Example in task 47 & Example in task 48 \\
\hline $\begin{array}{l}\text { Static } \\
\quad \text { proportionality }\end{array}$ & $\begin{array}{l}\text { Proportional } \\
\text { reasoning }\end{array}$ & $\frac{\text { water }}{\text { lemon juice }}=\frac{2}{1} \frac{\text { sugar }}{\text { lemon juice }}=\frac{1}{2}$ & $\begin{array}{l}7 \mathrm{dL}: 3 \frac{1}{2} \text { parts }=x \mathrm{dL}: 1 \text { part } \\
1 \text { part:31/2 parts }=x \mathrm{dL}: 7 \mathrm{dL}\end{array}$ \\
\hline $\begin{array}{l}\text { Dynamic } \\
\text { proportionality }\end{array}$ & $\begin{array}{r}\text { Proportional } \\
\text { reasoning }\end{array}$ & & $\begin{array}{l}\text { The total amount is } 3.5 \text { times } \\
\text { as much as the amount of } \\
\text { lemon juice }\end{array}$ \\
\hline- & Number facts & $2 \cdot 5=10$ & $7=2 \cdot 3.5$ \\
\hline $\begin{array}{l}\text { Static } \\
\text { proportionality }\end{array}$ & $\begin{array}{l}\text { Cross multiplication } \\
\text { algorithm }\end{array}$ & - & $\left(\frac{7}{3.5}=\frac{x}{1}\right) \quad 7 \cdot 1=3 \S \cdot \mathrm{x}$ \\
\hline- & Equation solving & $\begin{array}{l}\text { Exchanging } x \text { for } 5 \text { in each } \\
\quad \text { expression to interpret } \\
\text { water as } \\
2 \cdot 5=10 \text { and sugar as } \\
\frac{5}{2}=2.5 \text {. }\end{array}$ & $x+2 x+\frac{x}{2}=73.5 x=7 x=2$ \\
\hline $\begin{array}{l}\text { Dynamic } \\
\text { proportionality }\end{array}$ & Graphic & - & Graphic representation of $f(x)=31 / 2 \cdot x$ \\
\hline
\end{tabular}

\section{Transposition of Knowledge to Be Taught into Knowledge Actually Taught}

The classroom analysis is based on a sequence of seven episodes where the teacher explains the Lemon Squash Task to individual students. In the first four excerpts, we see the teacher's reasoning as she interprets, models, makes assumptions, uncovers her mistake, and revises her primary model (everyday context model). In excerpt 1 , the teacher starts by reading and interpreting the task for herself, explaining carefully and making sense of the proportions in the recipe as a whole. The teacher works with the two tasks together with the students for about $3 \mathrm{~min}$.

Excerpt 1: [Time into lesson 1: $20 \mathrm{~min} 35 \mathrm{sec}$ ]

T: Mhm, Eh, Then you should look here, (Points in the textbook.)

$\mathrm{S}_{1}$ : Yes

T: Then you should use this the whole time, it means here, that, if you have $\mathrm{x}$.

$\mathrm{S}_{1}: \mathrm{mm}$

T: amount of lemon juice, then you have two $\mathrm{x}$ of water. It means that you have twice as much water

$\mathrm{S}_{1}: \mathrm{mm}$

T: as lemon juice the whole time. 
$\mathrm{S}_{1}$ : yes

T: And, how much sugar is it? How much is the amount of sugar, if you compare it with lemon juice?

T: It is always

$\mathrm{S}_{1}$ : half

T: half, yes exactly

In order to make sense of the task, the teacher starts out to discuss the relations in the recipe and recontexualizes the task for the student by translating symbolic expressions into words. The textbook section is about expressions, not equations, but quite suddenly, the Lemon Squash Task appears, challenging students to model an equation making use of the given expressions $x, x / 2$, and $2 x$. The question "How much lemon juice is there in $7 \mathrm{dL}$ of lemon squash?" seems difficult because there are no clues in the preceding pages on how to model an equation. Our interpretation is that the teacher therefore uses the same technique as in the preceding task. She is quiet for some time, then she exclaims "Ah!" when she realizes that $7 \mathrm{dL}$ is the total amount of mixed drink, not a part (excerpt 2).

Excerpt 2: [Time into lesson 1: $21 \mathrm{~min} 31 \mathrm{sec}]$

T: So, then you can first calculate how much, (.)

Ah! it also says seven deciliters of mixed, yes.

$\mathrm{S}_{1}: \mathrm{mhm}$

T: eh, so this is how you need to think, it's (.) the liquid (.) that makes up the drink

When the teacher has realized her initial mistake, she considers the model of the task. Knowing that sugar dissolves in water ${ }^{4}$, she contemplates whether it contributes to the total volume. She wants to make sense of the given algebraic expressions in the recipe but her everyday knowledge tells her that sugar dissolves in water and does not increase the volume, so she discards the sugar and considers only the lemon juice and the water, which means, she needs to divide $7 \mathrm{dL}$ into three volume parts.

Excerpt 3:[Time into lesson 1: $22 \mathrm{~min} 1 \mathrm{sec}]$

$\mathrm{T}$ : and water gives twice as much (.) and it will be (.) $\mathrm{mmm}$ in itself. I wonder if sugar also gives some amount there? (.) I have to think, does it really, there is no amount of sugar, it just ends up in the liquid. Eh, this will be seven together.

\footnotetext{
$\overline{{ }^{4} \text { For a } 12.7 \% \text { sucrose solution-1 }} \mathrm{dL}$ (88 g) sugar, $4 \mathrm{dL}$ (400 g) water, $2 \mathrm{dL}$ (200 g) lemon juice - the sum of volumes is $7 \mathrm{dL}$, while the solution's actual experimental volume is $6.6 \mathrm{dL}$.
} 
$\mathrm{S}_{1}: \mathrm{mhm}$

T: Something plus something plus something will be seven.

When she realizes that $7 \div 3$ will result in a long decimal number, she states that they must have intended the sugar to be treated as if it did contribute to the total volume in the same way as the fluids (excerpt 4). She is avoiding the continuous variable, expecting the task to include only discrete numbers. In fact, the sugar does contribute, but not as much as the fluids, although the difference is quite small $(0.4 \mathrm{dL})$. Both everyday knowledge and scientific knowledge need to be put aside to make sense of the mathematical model. Although this is common in mathematical modeling processes, it may cause confusion if it is not made clear.

Excerpt 4: [Time into lesson 1: $22 \mathrm{~min} 45 \mathrm{sec}$ ]

T: That was a difficult calculation!

$\mathrm{S}_{1}: \mathrm{mm}$

T: Wasn't it? It would have been easier if it were six (.) deciliters there. Maybe they count, yes eh, I think they eh mean that they consider the sugar to give some amount. Because then I can work it out!

After this, the teacher solves the task by translating from an algebraic into a visual representation, drawing four lines representing the amount of each ingredient. The lengths of the lines are in proportion to the recipe: one line for lemon juice, two for water, and a line half as long for sugar, adding $1 / 2$ under the last line for clarification (Fig. 2). After drawing the lines, the teacher says she will try out what number is the right one, thus using trial and error as a solution technique. She suggests 2 and adds $2+2+$ $2+1=7$. When leaving to attend to another student, the teacher mutters " $\ldots$ what a complicated task that was!". The technique to represent numbers as lines, she informs us in the post-lesson interview, was something she learned when she was a student herself, and she still often relies on this technique when solving algebra tasks. Figure 2 shows the solution of task 48 from a student's notebook including the lines drawn by the teacher.

The second time the teacher explains this task to a student, she refers to her earlier experience, telling the student that the task is tricky and describing the mistake she made about the sugar contributing to the total (excerpt 5). She

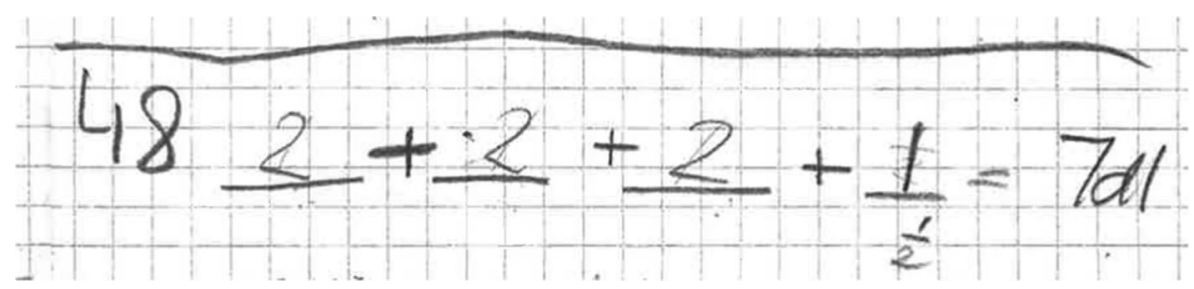

Fig. 2 Solution example of task 48. Note that the line is roughly four squares under digit 2 and two squares under digit 1 representing the relation between the ingredients 
underlines what is actually stated and makes the assumption she used in the earlier explanation.

Excerpt 5: [Time into lesson 2: $14 \mathrm{~min} 36 \mathrm{sec}$ ]

T: This is a bit tricky. When I solved this I had to use trial and error. Do you know why I thought it was difficult to solve? Because I don't think or I guessed that sugar didn't contribute to the volume in lemon squash. But of course it does. This is how I did it. (The teacher takes the pen and paper from the student, $\mathrm{S}_{2}$, and starts to draw lines.)

$\mathrm{T}$ : If it is seven deciliters mixed lemon squash. Uh, then it is, they write here that, something plus something two times is the secret number $x$. (.) plus half of the secret number. I write like this, so I will remember, it will be seven deciliters. A number plus a number plus a number plus half of the secret number will be seven. Can you try finding the number?

Throughout the following five times the teacher explains the task to different students, she sticks to her model but pays less and less attention to her initial misinterpretation of the solid dissolving in the liquids. Effort is mainly put into modeling the task as volume parts represented by lines and the use of trial and error. In total, the teacher explains the task seven times. Number issues reappear and students seem to hesitate if decimals are included. In the last two excerpts taken from the seventh episode in the sequence, we see how the teacher encourages the student to solve and reason about the first task (task 47, excerpt 6) in order to understand how the proportional relation works and connects to the algebraic representation, and then introduces the equation necessary for solving the second task (task 48, excerpt 7) using her line technique.

Excerpt 6: [Time into lesson 4: $44 \mathrm{~min} 38 \mathrm{sec}$ ]

T: mm, How much sugar do you need then?

$\mathrm{S}_{7}: \mathrm{Eh}$

T: Once again, you should put five deciliters in the x's place, if you put five there, after that you write the rest of the expression, five divided by two.

$\mathrm{S}_{7}$ : Is that possible?

T: Oh yes, nothing even but,

$\mathrm{S}_{7}:$ three, no, ehh, is it one?

T: five divided by two is not one, 
$\mathrm{S}_{7}$ : but, eh, two point five

T: two point five it is, yes you can check it out afterwards, two point five times two, two sets of two point five is five.

$\mathrm{S}_{7}$ : yes

T: mm, so two point five deciliters sugar. It means that this formula shows you that you have got half as much sugar as lemon juice, right?

$\mathrm{S}_{7}$ : yes

Excerpt 7: [Time into lesson 4: $46 \mathrm{~min} 2 \mathrm{sec}$ ]

T: It should be seven all together, of all this. (Points at the recipe in the book)

$\mathrm{S}_{7}: \mathrm{mm}$

T: and here we need to try out our way to find, eh, how much of each you need, (The teacher writes in the student's notebook) I usually make lines like this, one, I mean $\mathrm{x}$ means the same number all the time, do you follow?

$\mathrm{S}_{7}: \mathrm{mm}$

$\mathrm{T}$ : eh, Then we make a line for the lemon juice, we do not know what number to put there yet because it is an $\mathrm{x}$ there. And then we put it together with water and how much of this number should we use regarding water?

$\mathrm{S}_{7}$ : Eh five, aha no two.

T: It says times two, it should be double the amount.

$\mathrm{S}_{7}$ : yes.

T: because we will write the same number on these lines, I will make two lines, double the amount of water. mm

T: Eh then we have sugar, and this is tricky, how much was the amount of sugar?

$\mathrm{S}_{7}$ : two point five

T: Yes if you had five deciliters then it was two point five but if you compare two point five and five, what is the relation between them?

$\mathrm{S}_{7}$. Half 
T: It is half as much, yes, so it should be a half line here. This number we get three times and a half, do you follow my thoughts if I make these kinds of lines?

The teacher solves the task with the same technique each time, using lines and trial and error. The last time she develops her explanation by summing up the unknowns saying, "this number we get three times and a half." Of all the teachers' utterances this last sentence, uttered the seventh time she explains the task, is the only clear statement exposing some of the proportional reasoning afforded by the task. The obstacles embedded in the contextualization of the task have up to this point constrained the didactic transposition of knowledge of proportionality. In Table 3, we summarize the knowledge to be taught and the knowledge actually taught that emerged in our analysis in relation to the REM concerning proportionality as shown in Fig. 3. We have also included the modeling aspects of the knowledge taught in Table 3 as they were highlighted by the analysis. The term implicit is there used to describe reasoning that may be fundamentally multiplicative and therefore proportional without making the student aware of this and referring to the relationship as proportional.

\section{Discussion}

We have studied a teacher in the process of transposing knowledge embedded in a textbook task from knowledge to be taught into knowledge actually taught (Bosch \& Gascón, 2006). We argue that the teachers' interpretation of the task was constrained by the context in which the task was placed and by an existing didactical contract, which led her to discard her everyday experiences (the sugar does not contribute to the volume) as well as the scientific concept of volume, and did not allow her to detach from the textbook proposal, thus not inviting her students into a modeling process. By saying, "I think they mean that they consider the sugar to give some amount," she moves the focus of attention to the mathematics, losing the everyday connection (Jablonka \& Gellert, 2007). In the recontextualization process, the teacher used two models, one grounded in everyday knowledge (sugar dissolves) and another grounded in mathematical knowledge (sugar is an equal part). She recontextualized the recipe into lines with different lengths and successfully solved the task, subsequently repeating this solution technique each time with more detail, although the constraints of her

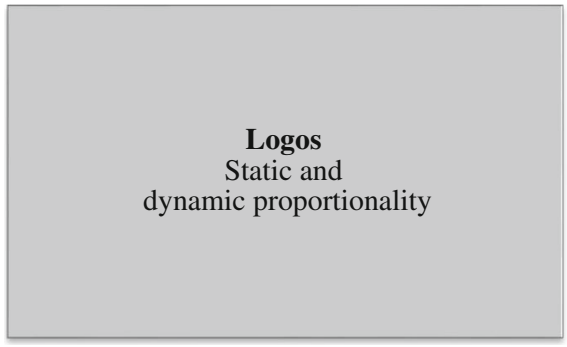

\section{Praxis}

Replacing a letter with a number Arithmetic calculation techniques Number facts (task 47) Explicit proportional reasoning to solve the problem directly or to set up an equation Cross multiplication Graphic representation Formal equation solving techniques (task 48)

Fig. 3 Reference epistemological model (REM) concerning proportionality relevant for the Lemon Squash Task 
Table 3 Summary of transposition of praxeologies

\begin{tabular}{|c|c|c|}
\hline & $\begin{array}{l}\text { Knowledge to be taught } \\
\text { The task in the context of the } \\
\text { textbook }\end{array}$ & $\begin{array}{l}\text { Knowledge actually taught } \\
\text { What the teacher says and does as she } \\
\text { interprets the task and explains it seven } \\
\text { times. }\end{array}$ \\
\hline $\begin{array}{l}\text { Logos: theoretical } \\
\text { models } \\
\text { (Theory and } \\
\text { Technology) }\end{array}$ & $\begin{array}{l}\text { Multiplicative relations } \\
\text { Proportional relations }\end{array}$ & Doubling and halving \\
\hline $\begin{array}{l}\text { Praxis: } \\
\text { (Task and } \\
\text { Technique): }\end{array}$ & $\begin{array}{l}\text { Task 47: } \\
\text { Representing an unknown number } \\
\text { by a symbol. } \\
\text { Replacing a letter with a number } \\
\text { Proportional reasoning } \\
\text { Task 48: } \\
\text { Interpreting algebraic expressions. } \\
\text { First encounter with setting up } \\
\text { an equation (taught in a later } \\
\text { unit of the book). } \\
\text { Solving using trial and error. } \\
\text { Proportional reasoning }\end{array}$ & $\begin{array}{l}\text { Task 47: } \\
\text { Replacing a letter with a number } \\
\text { Arithmetic calculation techniques Number } \\
\text { facts } \\
\text { Task } 48 \text { : } \\
\text { Interpreting algebraic expressions by } \\
\text { recontextualizing } \\
\text { and representing the sum of ingredients } \\
\text { visually as lines of proportional lengths. } \\
\text { Solving using trial and error. Doubling and halving } \\
\text { as implicit examples of proportional reasoning. }\end{array}$ \\
\hline Modeling & $\begin{array}{l}\text { Mathematical modeling can be } \\
\text { useful when solving everyday } \\
\text { situations (however, the chosen } \\
\text { situation does not require } \\
\text { representing an unknown with } \\
\text { a letter if treated as an everyday } \\
\text { mixing situation) }\end{array}$ & $\begin{array}{l}\text { Moves the task from an everyday context into the } \\
\text { context of mathematics: } \\
\text { Model } 1 \text { sugar dissolves (everyday context) } \\
\text { Model } 2 \text { sugar is an equal part (mathematical } \\
\text { context) }\end{array}$ \\
\hline
\end{tabular}

model were never made explicit and never developed into more explicit proportional reasoning. Regarding proportional reasoning, the teacher gets no further than doubling and halving in this lesson. Our hypothesis that teachers accept a word problem in school mathematics to be only artificially real and not necessarily aligned with everyday experiences was confirmed in this case. Different mixtures are not compared, but the whole idea of mixing water, juice, and sugar is an aspect of familiarity relevant as a context variable (Tourniaire \& Pulos, 1985) that clearly affects the solution procedure, at least for the teacher. By referring to the agency of the textbook authors, she indicated that it was to be expected in a word problem in a mathematics textbook.

Another constraint is that the task appeared in the algebra unit focusing on the use of symbolic notation. Constructing an equation was not something the students had been introduced to prior to this task, and therefore, it was not a solution technique the teacher intuitively used or expected her students to use. Also, the teacher did not expect difficult calculations with decimal numbers to appear in the algebra unit. When the teacher recontextualized the task, she expected the solution technique to be found in the textbook (Lithner, 2008; Verschaffel et al., 2000). Using the information and techniques provided by the textbook is a norm that influenced the teacher when making sense of the task. Proportional relationships, described as static or dynamic proportionality, embedded in the task became a 
background feature and did not stand out as affordances to the teacher. The Lemon Squash Task affords many opportunities of learning proportionality, which stayed hidden. As shown in the present episode, proportional relationships and proportional reasoning is an integral part of algebra and may appear in various parts of a textbook. Placing proportionality in a separate block, as in the Swedish national curriculum under the heading "Relationships and change" (see Table 1) does not help teachers to make relevant connections between mathematical ideas. Lack of connections between different mathematical domains is not an uncommon constraint of secondary school mathematics actually taught (Jablonka \& Johansson, 2010).

Affordances of the task can be seen in the way the task is related to the REM in Fig. 3. Both dynamic and static proportionality as theoretical models could be discussed in relation to this task as well as different solution techniques including explicit proportional reasoning. Most strikingly, we see that the theoretical models of the praxeology are only implicit in the textbook context and totally missing in the knowledge actually taught. The only solution technique suggested by the textbook is to use trial and error, which the teacher adopts in her explanation. Doubling and halving is used but without stressing proportional reasoning, which is therefore left implicit.

Our choice to analyze the task in relation to knowledge about algebra and proportional reasoning has highlighted specific affordances and constraints. A different analysis focusing the transposition of knowledge of problem solving or modeling, two other mathematical topics overarching several units in the textbook, may bring to the fore other affordances and constraints with the task. The methodological approach included the use of several cameras when recording classroom activities. Video observations of the whole class were a great advantage in the initial phase of analysis since it gave us an overview of the four lessons and all activities that went on. The episodes chosen were unique in respect to how much of her own work of transposition the teacher exhibited. Mostly, such work is done during planning hours and therefore not visible in the classroom. Although all four teachers in the study used the same textbook, the Lemon Squash Task was not treated explicitly during the recorded lessons in any of the other classrooms. Comparing different teachers' treatment of the same task would have added new features to our analysis and could be well worth investigating in further studies. The study has added to previous research on textbook tasks by looking at the treatment of a task in the ongoing work of teaching. Given the unique setting of this study, where a teacher is faced with a task to deal with ad hoc, in the flow of the lesson, we have been able to identify some constraining aspects in the process of didactic transposition.

We have shown that a textbook task can be seen as a cultural artifact greatly dependent on the context in which it is placed. Consequently, a task cannot be judged as good or bad in itself, and the learning opportunities a task designer sees in a task may not stand out as affordances to the teacher and consequently not be included in the transposition into knowledge actually taught. This suggests that textbook authors need to elaborate more on tasks in the teachers' guide, making affordances of a task explicit and including tutorial notes about learning. The Lemon Squash Task becomes exceptionally difficult because the intended mathematical relations are in conflict with both the scientific and the everyday concept of volume when mixing fluids and solid matter, implying that everyday concepts and common sense are not applicable here (Sullivan 
et al., 2003). We see it as an unfortunate choice of realistic context and suggest task designers pay a good deal of attention to both everyday experiences and scientific validity. The complexity of the task could be reduced by a change of measure space from volume (dL) to weight (gram), in which case, the physical state of the ingredients does not matter anymore.

Remillard (2005) identified a number of teacher variables that influence what is taught, and we acknowledge that these variables have great influence on the teacher's work. The teacher must have sufficient subject matter knowledge as well as pedagogical content knowledge to use the explorations of textbook tasks as a moment of learning, in which students develop the use of mathematical arguments as well as knowledge from everyday experiences and scientific knowledge to solve problems. In this setting we could see that the teacher did not teach proportionality and proportional reasoning although the task afforded it. This could be because the task was placed in an algebra context, but it could also be a result of the teacher's lack of experience in teaching proportional reasoning since it has not previously been an explicit part of the curriculum for these grades. Ben-Chaim, Keret and Ilany (2007) showed that teacher students had a pre-understanding of proportional reasoning as easy to teach, but after an intervention with tasks and research reports, they changed their minds about their own knowledge about proportional reasoning. In addition to teacher knowledge, Remillard (2005) also emphasized the participatory relationship between teacher and curriculum in the planning and enactment of curriculum. We have analyzed how affordances and constraints of a textbook task played out in the transposition of knowledge, so that the knowledge actually taught was a result of the way the task was interpreted by the teacher. The results indicate that teachers need to focus not only on their own ability to solve a textbook task and how to explain the solution of the task, but even more on questions concerning what students are expected to learn from the task, adopting a critical approach to the textbook. We conclude that it is not enough with a pretentious change in curriculum if mathematics knowledge is partitioned into blocks of core content without linking between the blocks. In particular, an overarching mathematical idea such as proportionality may not surface when it is embedded in other topics. The teacher in the episode here makes "normal" decisions influenced by the constraints of the didactic transposition under which she develops her instruction. To help the teachers with the didactic transposition, more has to be done by curriculum developers and textbook authors. The whole process of the didactic transposition needs to be considered - why mathematics should be taught in school and what mathematical knowledge should be taught as well as clear suggestions on how to teach it.

Acknowledgments This article is a development of a contribution to the ICMI Task Study 22 proceedings, 'The Lemon Squash Task' (Lundberg \& Kilhamn, 2013). The study is funded by NOS-HS (The Joint Committee for Nordic Research Councils for the Humanities and the Social Sciences), the Research School at the Centre for Educational Science and Teacher Research (CUL), Gothenburg University and The Royal Society of Arts and Sciences in Gothenburg. We also wish to thank the researchers in the VIDEOMAT project for the great help in collaborative video analysis and Anne Watson and Denisse Thompson for the valuable input during the ICMI22 conference.

Open Access This article is distributed under the terms of the Creative Commons Attribution 4.0 International License (http://creativecommons.org/licenses/by/4.0/), which permits unrestricted use, distribution, and reproduction in any medium, provided you give appropriate credit to the original author(s) and the source, provide a link to the Creative Commons license, and indicate if changes were made. 


\section{References}

Bayazit, I. (2013). Quality of the tasks in the new Turkish elementary mathematics textbooks: The case of proportional reasoning. International Journal of Science and Mathematics Education, 11(3), 651-682.

Ben-Chaim, D., Keret, Y. \& Ilany, B.-S. (2007). Designing and implementing authentic investigative proportional reasoning tasks: The impact on pre-service mathematics teachers' content and pedagogical knowledge and attitudes. Journal of Mathematics Teacher Education, 10(4-6), 333-340.

Boesen, J. (2006). Assessing mathematical creativity: Comparing national- and teacher-made tests, explaining differences and examining impact. (Doctoral Dissertation) Umeå, Sweden: Department of Mathematics and Mathematical Statistics, Umeå Universitet.

Bosch, M. \& Gascón, J. (2006). Twenty-five years of didactic transposition. International Commission on Mathematical Instruction Bulletin, 58, 51-65.

Bosch, M., García, F., Gascón, J. \& Ruiz Higueras, L. (2006). Reformulating "mathematical modelling" in the framework of the anthropological theory of didactics. In J. Novotná, H. Moraová, M. Krátká \& N. Stehlíková (Eds.), Proceedings of the 30th Conference of the International Group for the Psychology of Mathematics Education (Vol. 2, pp. 209-216). Prag: Charles University.

Brändström, A. (2005). Differentiated tasks in mathematics textbooks: An analysis of the levels of difficulty. (Licentiate thesis) Luleå: Luleå tekniska universitet.

Brousseau, G. (1997). Theory of Didactical Situations in Mathematics. 1970-1990 (N. Balacheff, M. Cooper, R. Sutherland, \& V. Warfield, Trans.). Dordrecht: Kluwer Academic Publishers.

Carlgren, I., Klette, K., Myrdal, S., Schnack, K. \& Simola, H. (2006). Changes in Nordic teaching practices: From individualized teaching to the teaching of individuals. Scandinavian Journal of Educational Research, 50(3), 301-326.

Carlsson, S., Liljegren, G. \& Picetti, M. (2004). Matte Direkt Matteborgen 6B [Direct math, Mathematics Castle, 6B]. Stockholm: Bonniers.

Chevallard, Y. (2006). Steps towards a new epistemology in mathematics education. In M. Bosch (Ed.), Proceedings of the 4th Congress of the European Society for Research in Mathematics Education (pp. 21-30). Barcelona: Universitat Ramon Llull.

da Ponte, J. P. \& Marques, S. (2007). Proportion in school mathematics textbooks: A comparative study. Paper presented at the 5th Congress of the European Society for Research in Mathematics Education. Larnaca: CERME.

Dowling, P. (1998). The sociology of mathematics education. Mathematical myths/pedagogic texts. London: Routledge Falmer.

Florensa, I., Bosch, M. \& Gascón, J. (2015). The epistemological dimension in didactics: two problematic issues. Paper presented at the 9th Congress of the European Society for Research in Mathematics Education. Prague: CERME.

Freudenthal, H. (1983). Didactical phenomenology of mathematical structures. Dordrecht: Reidel Publishing Company.

Goodwin, C. (1994). Professional vision. American Anthropologist, 96(3), 606-633.

Haggarty, L. \& Pepin, B. (2002). An investigation of mathematics textbooks and their use in English, French and German classrooms: Who gets an opportunity to learn what? British Educational Research Journal, 28(4), 567-590.

Howe, C., Nunes, T. \& Bryant, P. (2011). Rational number and proportional reasoning: using intensive quantities to promote achievement in mathematics and science. International Journal of Science and Mathematics Education, 9(2), 391-417.

Jablonka, E. \& Gellert, U. (2007). Mathematisation - demathematisation. In E. Jablonka \& U. Gellert (Eds.), Mathematisation and demathematisation. Social, Political and Educational Ramifications (pp. 1-18). Rotterdam: Sense publications.

Jablonka, E. \& Johansson, M. (2010). Using texts and tasks. In B. Sriraman, C. Bergsten, S. Goodchild, G. Pálsdóttir, B. Dahl, \& L. Haapasalo (Eds.), The First Sourcebook on Nordic Research in Mathematics Education (pp. 363-372). Charlotte, NC: Information Age Publishing.

Johansson, M. (2006). Teaching mathematics with textbooks: a classroom and curricular perspective (Doctoral Dissertation). Luleå: Luleå University of Technology.

Jordan, B. \& Henderson, A. (1995). Interaction analysis: Foundations and practice. The Journal of the Learning Sciences, 4(1), 39-103. 
Karplus, R., Pulos, S. \& Stage, E. K. (1983). Proportional reasoning of early adolescents. In R. Lesh \& M. Landau (Eds.), Acquisition of mathematics concepts and processes (pp. 45-90). Orlando: Academic.

Kirsch, A. (1969). Eine Analyse der sogenannten Schlussrechnung [An analysis of the so-called final statement]. Mathematische-Physikalische Semsterberichte, 16(1), 41-55.

Klette, K. (2007). Trends in research on teaching and learning in schools: Didactics meets classroom studies. European Educational Research Journal, 6(2), 147-160.

Lamon, S. (1993). Ratio and proportion: Connecting content and children's thinking. Journal for Research in Mathematics Education, 24(1), 41-61.

Lamon, S. (2007). Rational numbers and proportional reasoning: Toward a theoretical framework for research. In F. K. Lester (Ed.), Second handbook of research on mathematics teaching and learning: A project of the National Council of Teachers of Mathematics (pp. 629-667). Charlotte: Information Age Pub.

Langrall, C. W. \& Swafford, J. (2000). Three balloons for two dollars: Developing proportional reasoning. Mathematics Teaching in the Middle School, 6(4), 254-261.

Linell, P. (1992). The embeddedness of decontextualization in the contexts of social practices. In A. Heen Wold (Ed.), The dialogical aliernative. Towards a theory of language and mind (pp. 253-271). Oslo: Scandinavian University Press.

Lithner, J. (2008). A framework for creative and imitative reasoning. Educational Studies in Mathematics, 67, 255-276.

Lundberg, A. L. V., \& Kilhamn, C. (2013). The lemon squash task. In C. Margolinas (Ed.), ICMI study 22: Task Design in Mathematics Education (pp. 363-372). Oxford: University of Oxford.

Mellar, H. G. (1991). Modelling students' thinking on a proportional reasoning task. International Journal of Mathematics Education, Science and Technology, 22(1), 111-119.

Miyakawa, T. \& Winsløw, C. (2009). Didactical designs for students' proportional reasoning: An "open approach" lesson and a "fundamental situation". Educational Studies in Mathematics, 72(2), 199-218.

Noelting, G. (1980). The development of proportional reasoning and the ratio concept Part I: Differentiation of stages. Educational Studies in Mathematics, 11(2), 217-253.

Nunes, T., Desli, D. \& Bell, D. (2003). The development of children's understanding of intensive quantities. International Journal of Educational Research, 39, 651-675.

Remillard, J. (2005). Examining key concepts in research on teachers' use of mathematics curricula. Review of Educational Research, 75(2), 211-246.

Säljö, R. (2005). Lärande och kulturella redskap: Om lärprocesser och det kollektiva minnet [Learning and cultural tools: Learning processes and collective memory]. Stockholm: Nordstedts Akademiska Förlag.

Singh, P. (2000). Understanding the concepts of proportion and ratio constructed by two grade six students. Educational Studies in Mathematics, 43(3), 271-292.

Sullivan, P., Zevenbergen, R. \& Mousley, J. (2003). The contexts of mathematics tasks and the context of the classroom: Are we including all students? Mathematics Education Research Journal, 15(2), 107-121. doi:10.1007/BF03217373.

Swedish National Agency for Education (2011). Curriculum for the compulsory school, preschool class and the leisure-time centre 2011. Retrieved 20 July, 2015, from http://www.skolverket.se/publikationer.

Tourniaire, F. \& Pulos, S. (1985). Proportional reasoning: A review of the literature. Educational Studies in Mathematics, 16(2), 181-204.

Vergnaud, G. (1983). Multiplicative structures. In R. Lesh \& M. Landau (Eds.), Acquisition of mathematics concepts and processes (pp. 128-175). London: Academic.

Vergnaud, G. (1988). Multiplicative structures. In J. Hiebert \& M. J. Behr (Eds.), Number concepts and operations in the middle grades (Vol. 2, pp. 141-161). Hillsdale: National Council of Teachers of Mathematics.

Verschaffel, L., Greer, B. \& De Corte, E. (2000). Making sense of word problems. Lisse: Swets \& Zeitlinger. Vygotsky, L. S. (1986). Thought and language (A. Kozulin, Trans.). Cambridge: MIT Press.

Wright, V. (2014). Frequencies as proportions: Using a teaching model based on Pirie and Kierens's model of mathematical understanding. Mathematics Education Research Journal, 26(1), 101-128.

Wyndhamn, J. \& Säljö, R. (1997). Word problems and mathematical reasoning — a study of children's mastery of reference and meaning in textual realities. Learning and Instruction, 7(4), 361-382. 